\title{
Challenging Diagnosis of a Rare Case of Spontaneous Keloid Scar
}

\author{
William HC Tiong, ${ }^{\mathrm{a}, \mathrm{b}}$, Normala Hj Basiron ${ }^{\mathrm{a}}$
}

\begin{abstract}
Keloid scars are benign dermal collagenous lesions that arise in the reticular layer of the dermis as a result of a period of prolonged wound healing due to injurious cutaneous insult. It is diagnosed clinically by a history of injury preceding its appearance and its pathognomonic encroachment beyond the boundary of the original wound. There are multiple factors that predispose an individual to keloid scar formation but no single hypothesis sufficiently explained its complex pathogenesis. The spontaneity of keloid scar to arise de novo without prior cutaneous injury is very rare. Although the non-specific appearance of spontaneous keloid scar can resemble various malignant or benign tumors, it is of paramount importance to accurately diagnose it due to the difficulty and complexity of keloid scar treatment or the atrocious outcome of its mismanagement. Here, we presented a rare case of spontaneous keloid scar over an unusual site of occurrence, and its disfiguring consequences as a result of misdiagnosis and treatment. We also highlighted the diagnostic challenge facing many clinicians when spontaneous keloid scar occurred in an individual without significant predisposing factors. Therefore, extra vigilance should be exercised in our practice and the spontaneity origin of keloid scar should be borne in one's mind.
\end{abstract}

Keywords: Keloid; Preauricular scarring; Spontaneous scarring

\section{Introduction}

Keloid scar is a clinical diagnosis, usually preceded by a history of localized injury [1]. The term keloid was originally

Manuscript accepted for publication July 24, 2014

${ }^{a}$ Department of Plastic and Reconstructive Surgery, Hospital Kuala Lumpur, Jalan Pahang, Kuala Lumpur 50586, Malaysia

${ }^{\mathrm{b}}$ Corresponding Author: William HC Tiong, Department of Plastic and Reconstructive Surgery, Hospital Kuala Lumpur, Jalan Pahang, Kuala Lumpur 50586, Malaysia. Email: willhct@yahoo.com

doi: http://dx.doi.org/10.14740/jmc1887w described in 1800s as "cheloid", derived from the Greek word "chele" meaning "crab claw" because of its lateral extensions resembling the legs of a crab growing into normal tissue $[2,3]$. This invasion of surrounding dermis extension has become the pathognomonic feature of a keloid scar [4].

Keloid scar usually appears as firm, broad nodule and often erythematous with a shiny surface. Because of its common, non-specific clinical appearance and difficulty in treatment, it is important to differentiate keloid scar from other malignant or benign tumors $[5,6]$. The misdiagnosis of keloid scar for a tumor will have significant consequences as demonstrated in our case below.

One of the most important indicative information that leads to keloid scar diagnosis is the history of some form of injury prior to the appearance of the lesion [7]. Spontaneous keloid scars, that is, those keloidal lesions that develop without previous injury or surgery, are rare [8]. Here, we presented a rare case of spontaneous keloid scar on the unusual site of preauricular area of a 13-year-old boy without history of previous injury, and underlined its diagnostic challenge.

\section{Case Report}

A 13-year-old boy was referred to Plastic and Reconstructive

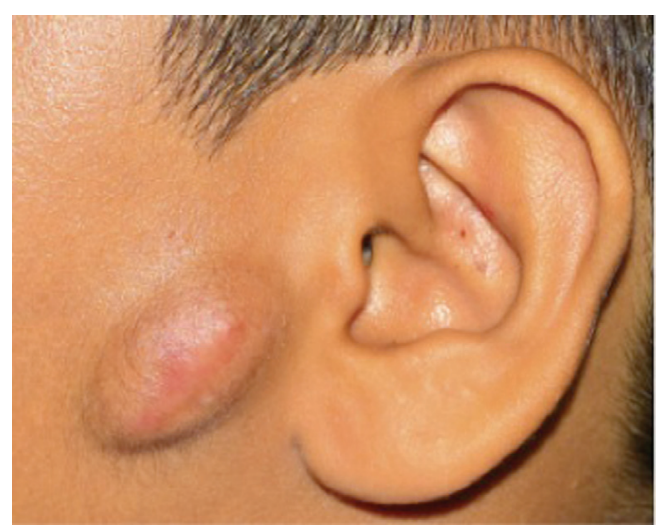

Figure 1. Preauricular nodule over the left cheek with no history of trauma. Note the pinkish mark overlying the skin of the nodule that indicated the site of biopsy. 


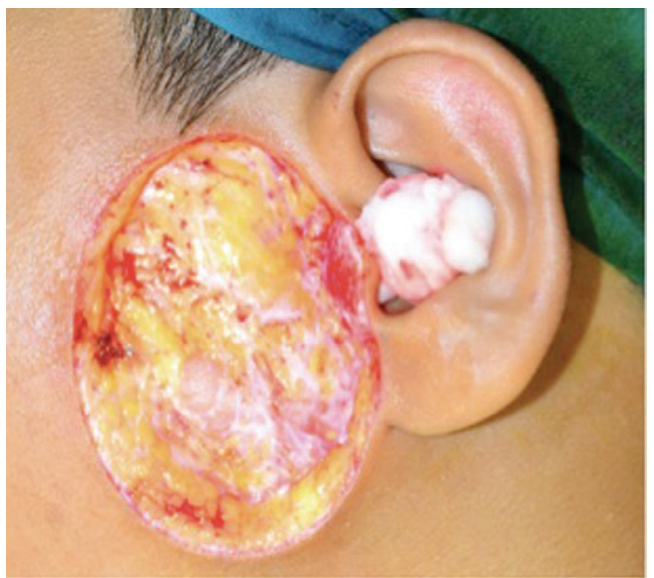

Figure 2. The lesion was excised with $1 \mathrm{~cm}$ peripheral margin and down to the parotidomasseteric fascia.

Surgery Unit for the management of left preauricular nodule (Fig. 1). The nodule had been present for 3 years. It started as a small, inconspicuous lesion that gradually increased in size. There was no associated pain or discharge. There was also no history of injury or past keloid scarring. The lesion was biopsied by the referring hospital and reported as desmoid-type fibromatosis (DF). Otherwise, the patient was healthy with unremarkable past medical history. There was no family history of keloid scarring or fibromatosis. No syndromic features were detected.

On examination, a well-circumscribed nodule measuring $3 \times 4 \mathrm{~cm}$ was noted over the left preauricular region. The overlying skin appeared normal with the exception of a pinkish, flat scar over the nodule that marked the site of previous incisional biopsy by the referring hospital. The nodule had a firm consistency but mobile. There was no evidence of infiltration to the adjacent tissue. There was also no palpable

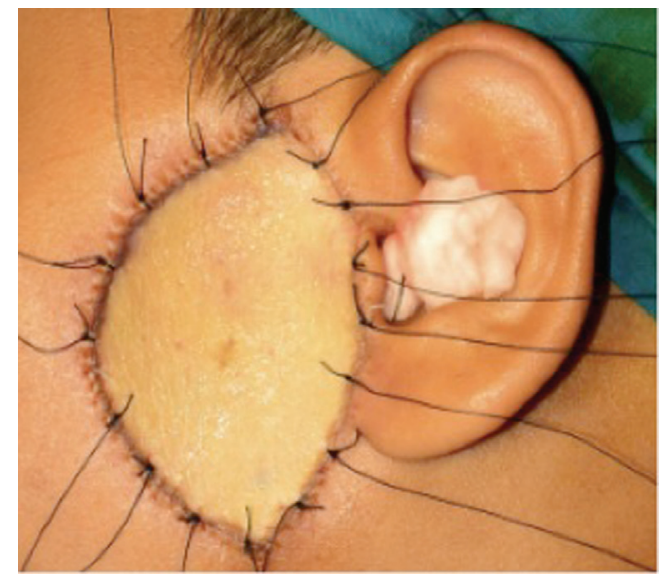

Figure 3. The preauricular defect was resurfaced with full thickness skin graft, taken from left supraclavicular region. The skin graft was secured with $5 / 0$ vicryl suture and $3 / 0$ silk as tie over bolus dressing.

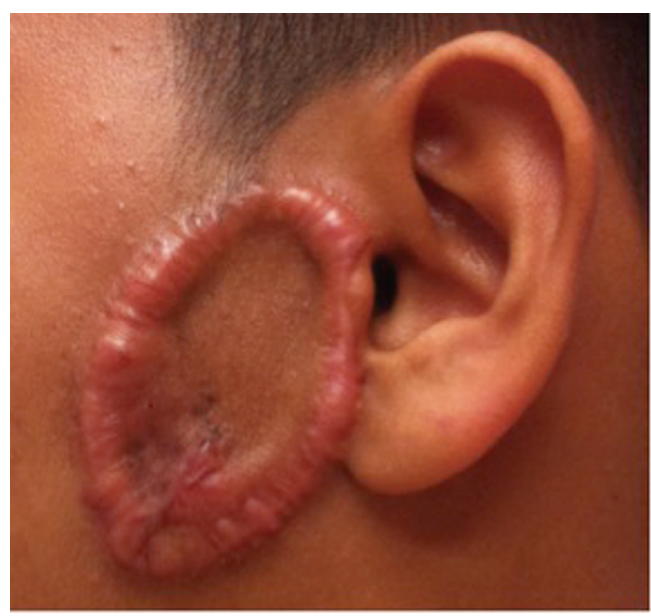

Figure 4. The formation of oval-shaped ring of keloid scar over the left preauricular region. The shape of the ring of keloid scar corresponded to the edge of the full thickness skin graft.

cervical lymphadenopathy.

Surgical excision and skin grafting were planned as primary management to achieve tumor clearance. Intraoperatively, the lesion was excised with a margin of $1 \mathrm{~cm}$ and down to the parotidomasseteric fascia (Fig. 2). The specimen was sent for histological analysis. The resultant defect was resurfaced with full thickness skin graft, taken from the left supraclavicular area (Fig. 3). The skin graft was secured with $5 / 0$ vicryl suture, and $3 / 0$ silk as tie-over bolus dressing.

Postoperatively, the skin graft was fully integrated and the course of recovery was unremarkable. The histopathology report of the specimen revealed it to be a keloid scar. At 3-month follow-up, the patient developed an oval-shaped ring of keloid scar, sparing the central portion of the graft (Fig. 4). The keloid scar was treated with topical silicon cream and intralesional steroid injection.

\section{Discussion}

Keloid scars are benign dermal collagenous lesions that arise in the reticular layer of the dermis during a prolonged wound healing process as the connective tissues response to trauma, inflammation, surgery or burns $[9,10]$. It often persists at the site of injury, has a high incidence of recurrence after excision, and always overgrows the boundaries of the original wound [9]. Clinically, it is typically raised, red or pink, and sometimes pruritic and painful [10]. The variability of the morphology of keloid scars is due to their evolving nature as a result of the extensibility of topical skin and the influence exerted by the external forces from adjacent joints and muscles based on their anatomical location [9]. It almost appears mushroom-shaped at first and subsequently, assumes specific forms such as butterfly-shaped in the mid chest area, 
propeller-shaped over the deltoid region, and bulbous on the earlobe including being nodular on the face as in our case.

The occurrence of keloid scar is commonest in patients 10 - 30 years of age [4]. It has a predilection for anterior chest especially presternal area, shoulders, upper arm, upper back, back of the neck and earlobes [2, 11]. Individuals of all ethnic backgrounds can form keloid scars but it is 15 times more prevalent in black population than in white $[2,3]$. It is also more common in teenager during puberty and women during pregnancy [3].

The cause of keloid scars remains largely unknown and no single hypothesis can sufficiently explained its formation [5]. The pathogenesis of keloid scar is complex, which involves the interplay of multiple factors such as genetic, hormonal, immunogenic and environmental factors [2]. There are theories such as the collagen turnover hypothesis, the tension hypothesis, the genetic immune dysfunction hypothesis and the sebum reaction hypothesis, but none solely accounted for their pathogenesis [12]. Patients, who are syndromic, are also more susceptible [13].

To date, there has been very few isolated spontaneous keloid scar cases reported in the literature [5, 14]. We reported a case of a 13-year-old boy with unexpected spontaneous keloid scar on the left preauricular region of the cheek without being preceded by any injury. The patient did not have family history of keloid scarring nor had he history of previous keloid scar formation elsewhere on his body. The location of keloid scar on the left preauricular region was very unusual. To our knowledge, there has not been any case of keloid scar described over the preauricular region in the literature. Other than his age as teenager in which keloid scar is known to affect, he had no known risk factor for keloid scarring [3]. His diagnosis was, therefore, challenging because of the unsuspected anatomical site involved and the absence of history of skin injury or family history of keloid scarring.

As a result of the rarity of spontaneous keloid scar, it is important to bear in one's mind the differential diagnosis of lesions resembling keloid scar. This is particularly important because various malignant and benign tumors can mimic keloid scar $[5,6]$. This is exemplified in our case in which the initial biopsy revealed it as DF. Among the malignant tumors that mimic keloid scars are dermatofibrosarcoma protuberans, trichilemmal carcinoma and keloidal basal cell carcinoma [5]. In addition to malignant skin conditions, there are a few benign conditions that also clinically resemble keloid scar $[5,6]$. These included nodular scleroderma, keloidal scleroderma, sclerotic neurofibroma, keloidal granuloma, erythema elevatum diutinum, dermatofibroma, penile edema, pseudoangiomatous hyperplasia, lichen sclerosus, apocrine cystadenoma, adult-onset juvenile xanthogranuloma, chondroid syringoma and subcutaneous eosinophilic lymphoid granuloma [5].

In general, a decision to biopsy a keloid scar should not be taken lightly because even a small wound from a minor surgical procedure may promote keloid scar growth [5]. However, biopsy for anomalous or unusual cases of keloid scar is justified [5]. In our case, histological biopsy was obtained by the referring hospital to confirm the diagnosis of the keloid scar due to its unusual location over the preauricular region, the absence of a past history of injury or trauma and the lack of significant predisposing factors. Unfortunately, the biopsied specimen was diagnosed histologically as DF.

DF is a rare monoclonal proliferative disease of fibroblastic origin [15]. Although it is a benign tumor, it is regarded as an aggressive tumor because of their locally infiltrative growth and high recurrence rate. Its mainstay of treatment remains surgical with wide resection margins advocated [16]. This had led us to excise the lesion with $1 \mathrm{~cm}$ margin and down to parotidomasseteric fascia.

Unfortunately, it is not always easy to make an accurate diagnosis of keloid scar based on its clinical appearance or even histopathologically especially due to its evolving nature $[17,18]$. This fact is highlighted in our case in which a histological misinterpretation of the biopsied specimen occurred. The accurate diagnosis of keloid scar carries significant implication, because a misdiagnosis will subject the patient to unnecessary biopsy or excision, which is illustrated in our case, can cause significant disfigurement through its recurrence. Our case, therefore, highlighted the challenge of managing keloid scar as an entity and more vigilance should be held in our practice while acknowledging the possible spontaneity of their occurrence.

\section{Conclusion}

Spontaneous keloid scars pose a significant diagnostic challenge to any clinician. Because of their rarity and variability in their clinical course, attending clinician should exercise a careful note when treating this condition. Any misstep along the way can lead to costly and disfiguring outcomes. All clinicians should be extra vigilant and the spontaneity nature of keloid scarring should continue to remain in one's mind.

\section{Grant Support}

Not applicable.

\section{Conflict of Interest}

Nil.

\section{References}

1. Marneros AG, Krieg T. Keloids--clinical diagnosis, 
pathogenesis, and treatment options. J Dtsch Dermatol Ges. 2004;2(11):905-913.

2. Hunasgi S, Koneru A, Vanishree M, Shamala R. Keloid: A case report and review of pathophysiology and differences between keloid and hypertrophic scars. J Oral Maxillofac Pathol. 2013;17(1):116-120.

3. Lindsey WH, Davis PT. Facial keloids. A 15-year experience. Arch Otolaryngol Head Neck Surg. 1997;123(4):397-400.

4. Smith OJ, McGrouther DA. The natural history and spontaneous resolution of keloid scars. J Plast Reconstr Aesthet Surg. 2014;67(1):87-92.

5. Ogawa R, Akaishi S, Hyakusoku H. Differential and exclusive diagnosis of diseases that resemble keloids and hypertrophic scars. Ann Plast Surg. 2009;62(6):660664.

6. Yeh SW, Lee WR, Hu CH, Tsai HH. Kimura's disease mimicking an earlobe keloid. Clin Exp Dermatol. 2010;35(4):e97-99.

7. Gulamhuseinwala N, Mackey S, Meagher P, Powell B. Should excised keloid scars be sent for routine histologic analysis? Ann Plast Surg. 2008;60(2):186-187.

8. Monarca C, Maruccia M, Palumbo F, Parisi P, Scuderi $\mathrm{N}$. A rare case of postauricular spontaneous keloid in an elderly patient. In Vivo. 2012;26(1):173-175.

9. Bayat A, Arscott G, Ollier WE, Ferguson MW, Mc Grouther DA. Description of site-specific morphology of keloid phenotypes in an Afrocaribbean population. $\mathrm{Br}$
J Plast Surg. 2004;57(2):122-133.

10. English RS, Shenefelt PD. Keloids and hypertrophic scars. Dermatol Surg. 1999;25(8):631-638.

11. Lee JY, Yang CC, Chao SC, Wong TW. Histopathological differential diagnosis of keloid and hypertrophic scar. Am J Dermatopathol. 2004;26(5):379-384.

12. Al-Attar A, Mess S, Thomassen JM, Kauffman CL, Davison SP. Keloid pathogenesis and treatment. Plast Reconstr Surg. 2006;117(1):286-300.

13. Gulec AT, Karaduman A, Seckin D. Noonan syndrome: a case with recurrent keloid formation. Cutis. 2001;67(4):315-316.

14. Mandal A, Imran D, Rao GS. Spontaneous keloids in siblings. Ir Med J. 2004;97(8):250-251.

15. Colombo C, Gronchi A. Desmoid-type fibromatosis: what works best? Eur J Cancer. 2009;45(Suppl 1):466467.

16. Min R, Zun Z, Lizheng W, Minjun D, Shengwen L, Wenjun Y, Chenping Z. Oral and maxillofacial desmoidtype fibromatoses in an eastern Chinese population: a report of 20 cases. Oral Surg Oral Med Oral Pathol Oral Radiol Endod. 2011;111(3):340-345.

17. Ogawa R, Akaishi S, Izumi M. Histologic analysis of keloids and hypertrophic scars. Ann Plast Surg. 2009;62(1):104-105.

18. Wong TW, Lee JY. Should excised keloid scars be sent for routine histologic analysis? Ann Plast Surg. 2008;60(6):724. 